\title{
Efeito do silício no desenvolvimento e na nutrição mineral de copo-de-leite ${ }^{(1)}$
}

\author{
ELKA FABIANA APARECIDA ALMEIDA(2), PATRÍCIA DUARTE DE OLIVEIRA PAIVA ${ }^{(3)}$, JANICE GUEDES DE CARVALHO(4), \\ NILMA PORTELA OLIVEIRA ${ }^{(5)}$, JULIANA FONSECA ${ }^{(6)}$, DANIELLA NOGUEIRA MORAES CARNEIRO(6)
}

\begin{abstract}
RESUMO
Estudos sobre o efeito do silício na produção de flores-de-corte ainda são bastante escassos. O silício pode afetar a produção vegetal por meio de várias ações indiretas, como melhorar a arquitetura das plantas, com folhas mais eretas, diminuindo o autossombreamento, e reduzir a incidência de patógenos. Assim, este trabalho teve como objetivo avaliar o efeito do silício no desenvolvimento da planta e na produção de inflorescências de copo-de-leite. Mudas de copo-de-leite provenientes da micropropagação, depois de aclimatizadas, foram transplantadas para vasos de $7 \mathrm{dm}^{-3}$ com substrato à base de latossolo vermelho, areia lavada e esterco bovino curtido, na proporção de 2:1:1. Após o transplante, as plantas receberam a adubação silicatada, via substrato, utilizando-se as concentrações de $25,50,75$ e $100 \mathrm{mg} \mathrm{dm}^{-3}$ de silício, e uma testemunha que não recebeu essa adubação. Utilizou-se o delineamento em blocos casualizados com 4 repetições e 3 plantas por parcela, sendo uma planta por vaso. As plantas foram avaliadas quanto às características de desenvolvimento, produção de inflorescências e teores de nutrientes no substrato, na folha e nas inflorescências. Não houve diferença entre os tratamentos para o desenvolvimento das plantas e produção de inflorescências. O teor de silício nas folhas foi aumentado com as doses de silicato de potássio fornecidas. A utilização de silicato de potássio aumenta o pH do substrato e a absorção de enxofre. Assim, conclui-se que as plantas de copo-de-leite não respondem à adubação silicatada ou a concentração de silício utilizada pode ter sido insuficiente.
\end{abstract}

Palavras chave: Zantedeschia aethiopica, silicato de potássio, floricultura.

\section{Effect of silicon on development and mineral nutrition of calla lily plants}

The number of studies on the effect of silicon in cut flowers is still small. The silicon can affect vegetal production by many indirect reasons, such as improving the plants architecture, with more erect leaves, decreasing the self shading, and decreasing the pathogens incidence. Thus, the aim of this present work was to evaluate the silicon in the plant development and yield of calla lily inflorescences. Micropropagated calla lily seedlings, after acclimatization, were transplanted to $7 \mathrm{dm}^{-3}$ pots with red oxisol, washed sand and manure as substrate, in the proportion of 2:1:1. After transplanted the plants received silicon fertilizer in substrate with concentrations of $25,50,75$ and $100 \mathrm{mg} \mathrm{dm}^{-3}$ of silicon and a control with no silicon. It was used a randomized block design with four replicates and three plants per plot. The plants were evaluated according to the development characteristics, inflorescences production and nutrient content in substrate, in the leaves and in the inflorescences. There were no differences among the treatment for the development of the inflorescence production. The content of silicon in the leaves was increased with the silicon concentrations given. The use of potassium silicate increases the $\mathrm{pH}$ of the substrate and the absorption of sulfur. Silicon fertilizer did not influence the calla lily development or the silicon concentration used might have been insufficient. Key words: Zantedeschia aethiopica, potassium silicate, floriculture.

\section{INTRODUÇÃO}

Os elementos minerais que estimulam o crescimento, mas não são essenciais, ou que são essenciais apenas para algumas espécies de plantas, ou sob condições específicas, são considerados elementos benéficos (FURLANI, 2004). São importantes no crescimento e desenvolvimento normal de algumas plantas, mas sua ausência não é considerada um fator limitante. Dentre os elementos considerados benéficos, pode- se destacar o silício (KORNDÖRFER, 2006).

Os efeitos benéficos da absorção e acumulação de silício, em geral, estão relacionados com as funções estruturais e a defesa das plantas, isto é, o silício pode afetar a produção vegetal por meio de várias ações indiretas, como proporcionar melhor arquitetura das plantas (folhas mais eretas), e assim, diminuir o autossombreamento; reduzir o acamamento; aumentando a rigidez estrutural dos tecidos; amenizar a toxidez de $\mathrm{Fe}, \mathrm{Mn}, \mathrm{Al}$, e $\mathrm{Na}$ e diminuir a incidência de

\footnotetext{
${ }^{(1)}$ Recebido para publicação em 30/08/2007 e aceito em 12/01/2010

${ }^{(2)}$ Pesquisadora, Dra., Empresa de Pesquisa Agropecuária de Minas Gerais, EPAMIG-CTSM-FERN, BR 494 - Km 2, Colônia do Bengo, CTAN, Cep 36300-000, São João Del Rei, MG, elka@epamig.br

${ }^{(3)}$ Prof. Dra., Departamento de Agricultura da Universidade Federal de Lavras (UFLA). Caixa Postal 3037, Cep 37200-000, Lavras, MG. pdolivei@ufla.br

${ }^{(4)}$ Prof. Dra., Departamento de Ciências dos Solos (UFLA), janicegc@ufla.br,

${ }^{(5)}$ Acadêmica do curso de Agronomia (UFLA) nilmaportela@yahoo.com.br, daninog27@yahoo.com.br,

${ }^{(6)}$ Acadêmica do curso de Engenharia Florestal (UFLA), julianafonseca2005@ufla.br.
} 
patógenos (KORNDÖRFER, 2006). Esses efeitos benéficos são possíveis porque o silício é depositado nas paredes das células dos vasos do xilema, o que confere rigidez e resistência, importantes na prevenção da compressão dos vasos sob elevada taxa de transpiração, do acamamento das plantas e, também, da invasão de patógenos e parasitas no córtex (FURLANI, 2004).

Segundo KORNDÖRFER (2006), em solos pobres em silício disponível, o uso de silicatos geralmente eleva o teor de silício nas plantas, resultando em aumentos de produtividade, principalmente em gramíneas (arroz, cana-de-açúcar, milheto, sorgo, trigo, aveia, milho, etc.), mas também em outras espécies como soja, feijão, alface, pepino, morango. Entretanto, há resultados divergentes sobre a produtividade das plantas em função da adubação silicatada, com relatos de incremento na produtividade de grãos em arroz (BARBOSA FILHO et al., 2001) e ausência de resposta também para a cultura do arroz (SILVA e BOHNEN, 2001; MAUAD et al., 2003) e tomateiro (LANA et al., 2003; PEREIRA et al., 2003).

Os estudos sobre o efeito do silício no segmento da floricultura ainda são bastante restritos. RODRIGUES (2006) avaliou diferentes doses de silício fornecidas por meio da fertirrigação para crisântemo cultivado em vaso e observou a produção de plantas de melhor qualidade quando a dose 37,5 $\mathrm{mg} \mathrm{L}^{-1}$ foi utilizada.

O copo-de-leite constitui uma das flores de corte mais tradicionalmente apreciadas no Brasil. Simboliza a pureza e, por isso, é bastante utilizado na composição de arranjos florais, principalmente em decorações de casamentos (ALMEIDA e PAIVA, 2004). Considerando os benefícios observados para outras espécies, é necessário avaliar o efeito do silício no desenvolvimento das plantas e na qualidade das flores produzidas, principalmente para espécies que apresentam importância comercial, como o copo-de-leite. Assim, este trabalho teve como objetivo avaliar o efeito da adubação silicatada no desenvolvimento e na produção de inflorescências de copo-de-leite, bem como os teores de silício e dos demais nutrientes no substrato e na planta.

\section{MATERIAL E MÉTODOS}

O experimento foi conduzido em casa de vegetação do Departamento de Agricultura da Universidade Federal de Lavras, MG, no período de junho de 2006 a janeiro de 2007. O município de Lavras apresenta coordenadas geográficas $21^{\circ} 14^{\prime} 30^{\prime \prime} \mathrm{S}$ e $45^{\circ} 00^{\prime} 10^{\prime} \mathrm{W}$, altitude de $918 \mathrm{~m}$ e precipitação média anual de 1.529,7 mm (BRASIL, 1992). Segundo a classificação climática de Köppen, o clima é do tipo Cwa, com características $\mathrm{Cwb}$, apresentando duas estações definidas: seca com temperaturas mais baixas, de abril a setembro, e chuvosa, com temperaturas mais elevadas, de outubro a março.

Foram utilizadas mudas de copo-de-leite (Zantedeschia aethiopica) produzidas por propagação in vitro. As mudas foram retiradas do laboratório e aclimatizadas em estufa de nebulização intermitente por um período de 60 dias, em substrato Plantmax ${ }^{\circledR}$, disposto em bandejas de plástico. Quando as mudas apresentaram altura média de $7 \mathrm{~cm}$, foram transplantadas para vasos de $7 \mathrm{dm}^{-3} \mathrm{em}$ substrato preparado a partir de uma mistura de latossolo vermelho, esterco bovino curtido e areia lavada na proporção de 2:1:1 para permitir a aeração e favorecer a percolação da água. Os dados referentes às características do substrato antes da aplicação dos tratamentos podem ser observados na tabela 1 .

Quatro meses após o transplante das mudas, realizou-se a aplicação dos tratamentos, que consistiram na utilização de diferentes doses de silício $\left(25,50,75\right.$, e $\left.100 \mathrm{mg} \mathrm{dm}^{-3}\right)$ aplicado via substrato, mais a testemunha que não recebeu a adubação silicatada. Utilizou-se, como fonte de silício, o silicato de potássio, o qual apresenta as concentrações de $55 \%$ de $\mathrm{SiO}_{2}$ e $22 \%$ de $\mathrm{K}_{2} \mathrm{O}$. Para isolar o efeito do silício, foi realizada adubação de correção para potássio de forma que todos os tratamentos recebessem a mesma concentração deste elemento.

A adubação de plantio seguiu a recomendação de MALAVOLTA e MURAOKA (1985) (adaptada) para adubações em vasos para experimentos. Dessa forma, foram fornecidos: $300 \mathrm{mg} \mathrm{dm}^{-3}$ de $\mathrm{N}$ (parcelados em duas

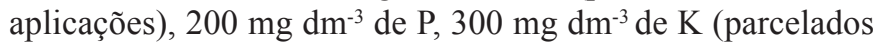
em duas aplicações), $75 \mathrm{mg} \mathrm{dm}^{-3} \mathrm{de} \mathrm{Ca}, 30 \mathrm{mg} \mathrm{dm}^{-3} \mathrm{de} \mathrm{Mg}$, $50 \mathrm{mg} \mathrm{dm}^{-3}$ de S, 0,5 $\mathrm{mg} \mathrm{dm}^{-3} \mathrm{de} \mathrm{B}, 1,5 \mathrm{mg} \mathrm{dm}^{-3} \mathrm{de} \mathrm{Cu}^{-3}, 0 \mathrm{mg}$ $\mathrm{dm}^{-3} \mathrm{de} \mathrm{Fe}, 0,1 \mathrm{mg} \mathrm{dm}^{-3}$ de Mo e $5 \mathrm{mg} \mathrm{dm}^{-3} \mathrm{de} \mathrm{Zn}$.

As plantas foram cultivadas sob sombreamento de $50 \%$ proporcionado pela tela sombrite ${ }^{\circledR}$ disposta dentro da estufa. A temperatura média durante o período experimental variou de $15,5^{\circ}$ a $27,5^{\circ} \mathrm{C}$ com umidade relativa do ar, em média, de $70 \%$.

O delineamento experimental utilizado foi o de blocos casualizados com quatro repetições, três plantas por parcela e uma planta por vaso. Os dados foram submetidos à análise de variância e regressão polinomial por meio do software Sistema de Análise de Variância para Dados Balanceados (Sisvar) (FERREIRA, 2000).

\subsection{Avaliações \\ 2.1.1 Caracteres agronômicos}

As inflorescências produzidas durante o período experimental foram colhidas assim que apresentaram padrão para colheita (espata totalmente expandida e ausência de pólen) conforme estabelecido por NOWAK e RUDNICKI (1990) e SALINGER (1991). Após a colheita, realizada ao longo do período experimental, cada inflorescência foi avaliada quanto à qualidade, observando-se o comprimento $\mathrm{e}$ diâmetro da haste, largura e comprimento da espata.

Seis meses após a aplicação dos tratamentos, as plantas foram avaliadas quanto às características de desenvolvimento, que consistiam na observação de número, largura e comprimento das folhas, altura da planta, número de brotos e número de folhas dos brotos.

Após a realização das avaliações agronômicas, as plantas foram segmentadas em folhas, rizomas e raízes, sendo estas partes lavadas separadamente em água corrente e, posteriormente, em água destilada, evitando-se, desta forma, possíveis contaminações por fontes externas. Este mesmo 
procedimento foi realizado com as inflorescências colhidas no decorrer do período experimental. Em seguida, todas as amostras (inflorescências, folhas, raízes e rizomas) foram acondicionadas em sacos de papel permeável, devidamente etiquetados e colocadas a secar em estufa de circulação forçada com temperatura de $65^{\circ}$ a $70^{\circ} \mathrm{C}$ até o peso constante, realizando-se então a determinação da matéria seca.

\subsubsection{Análises químicas das folhas e inflorescências}

Após a secagem, procedeu-se também à moagem para posterior análise química das folhas e das inflorescências, determinando-se os teores de $\mathrm{N}, \mathrm{P}, \mathrm{K}, \mathrm{Ca}, \mathrm{Mg}, \mathrm{S}, \mathrm{B} \mathrm{Cu}, \mathrm{Fe}$, $\mathrm{Zn}$ e $\mathrm{Mn}$, seguindo os métodos descritos por MALAVOLTA et al. (1997). Além disso, foi realizada a avaliação do teor de silício nos tecidos das inflorescências e das folhas, segundo os métodos propostos por GALLO e FURLANI (1978).

\subsubsection{Análises químicas do substrato}

Após a colheita das plantas, foi realizada amostragem do substrato em todos os tratamentos e repetições para realização das análises dos atributos químicos: $\mathrm{pH}$ (em água), $\mathrm{P}$ ( $\mathrm{mg} \mathrm{dm}^{-}$ $\left.{ }^{3}\right), \mathrm{K}\left(\mathrm{mg} \mathrm{dm}^{-3}\right), \mathrm{Zn}\left(\mathrm{mg} \mathrm{dm}^{-3}\right), \mathrm{Fe}\left(\mathrm{mg} \mathrm{dm}^{-3}\right), \mathrm{Mn}\left(\mathrm{mg} \mathrm{dm}^{-3}\right) \mathrm{e}$ $\mathrm{Cu}\left(\mathrm{mg} \mathrm{dm}^{-3}\right)$ com extrator Mehlich $1, \mathrm{Ca}\left(\mathrm{cmol}_{\mathrm{c}} \mathrm{dm}^{-3}\right)$ e $\mathrm{Mg}$ $\left(\mathrm{cmol}_{\mathrm{c}} \mathrm{dm}^{-3}\right)$ com extrator $\mathrm{KCl}, \mathrm{B}\left(\mathrm{cmol}_{\mathrm{c}} \mathrm{dm}^{-3}\right)$ com extrator água quente, $\mathrm{S}\left(\mathrm{mg} \mathrm{dm}^{-3}\right)$ com extrator fosfato monocálcico em ácido acético. Além disso, realizou-se a análise do silício disponível no substrato $\left(\mathrm{mg} \mathrm{dm}^{-3}\right)$ com extrator cloreto de cálcio.

\section{RESULTADOS E DISCUSSÃO}

\subsection{Efeito das doses de silício no substrato}

As concentrações de silício avaliadas proporcionaram diferenças significativas nos atributos químicos do substrato, observando-se que as doses mais elevadas proporcionaram aumento do teor de silício. Observa-se que o teor de silício no substrato aumentou significativamente quando doses superiores a $35 \mathrm{mg} \mathrm{dm}^{-3}$ foram utilizadas (figura 1).

Constataram-se também aumentos significativos do $\mathrm{pH}$ com a aplicação de silício (figura 2). Segundo FURTINI NETO et al. (2001) após reações no solo, os fertilizantes, em função da forma química dos nutrientes, podem acidificar, alcalinizar ou não alterar a acidez do solo. Assim, o aumento do $\mathrm{pH}$ do substrato constatado neste experimento ocorreu devido ao silicato de potássio utilizado, que apresenta $\mathrm{pH}$ 7,5. Além disso, segundo MALAVOLTA (2006), os silicatos têm poder de neutralização do solo.

Observou-se que não houve diferença significativa nos teores de macronutrientes no substrato em função das doses de silício estudadas (tabela 2), assim como dos teores de micronutrientes no substrato (tabela 3 ).

\subsection{Efeito das doses de silício na planta}

As doses de silício aplicadas não influenciaram o desenvolvimento das plantas de copo-de-leite. Como pode ser observado na tabela 4, não houve diferença significativa entre as plantas que receberam diferentes doses de silício e a testemunha, as quais apresentaram médias equivalentes, quanto às características avaliadas.

A produção de matéria seca das plantas não foi afetada pelas doses de silício, ou seja, a mesma produção de matéria seca foi observada, nas diferentes partes da planta, comparando-se as diferentes doses de silício e a testemunha. Em média, as plantas apresentaram 8,27 g de matéria seca nas folhas, 14,5 g no rizoma e 4,73 g nas raízes (tabela 5). De forma semelhante, MAUAD et al. (2003) constataram que as diferentes doses de silício aplicadas na cultura do arroz não proporcionaram alterações significativas na matéria seca da planta.

Independentemente das doses estudadas, pela separação das diferentes partes da planta para avaliação da quantidade de matéria seca, é possível afirmar que as plantas de copode-leite acumulam maiores reservas nos rizomas, os quais possuem maior peso.

Considerando o teor de silício na planta, houve diferença significativa entre as doses de silício utilizadas, e, como pode ser observado na figura 3, ocorreu incremento do teor deste nutriente nas folhas das plantas de copo-de-leite nas doses mais elevadas de silicato aplicadas no substrato.

Entre os macronutrientes analisados, observou-se aumento do teor de enxofre nas folhas de copo-de-leite à medida que ocorreu aumento das doses de silício fornecidas, ilustrado pela equação linear que proporcionou melhor explicação para o comportamento do teor de $\mathrm{S}$ nas folhas em função do teor de silício no substrato (figura 4).

Em decorrência do fato de a adsorção do $\mathrm{SO}_{4}{ }^{2-}$ ser reduzida pela elevação do $\mathrm{pH}$, a concentração de sulfato é menor quanto maior for o $\mathrm{pH}$, em virtude de maiores perdas por lavagem e pela absorção pelas plantas, uma vez que o sulfato torna-se mais disponível no solo (MELLO et al., 1983). Como mencionado anteriormente, o $\mathrm{pH}$ do substrato foi alterado com as doses de silicato de potássio, permitindo inferir que a disponibilidade de enxofre foi favorecida pelos os tratamentos, disponibilizando maior teor deste nutriente na solução do solo para absorção pelas plantas. Possivelmente, por causa da menor adsorção do $\mathrm{SO}_{4}{ }^{2-}$, pode ter ocorrido lixiviação do enxofre e, estatisticamente, o teor desse nutriente no substrato não foi influenciado pelos tratamentos.

Como pode ser observado na tabela 6 , verificou-se que não houve diferença significativa entre os teores dos demais macronutrientes analisados nas folhas das plantas cultivadas em substrato com diferentes doses de silício e testemunha. SILVA e BOHNEN (2001), que estudaram o acúmulo de nutrientes pelo arroz em solução nutritiva com e sem adição de silício, também observaram que a absorção de silício pelas plantas não alterou significativamente os teores de macronutrientes no colmo e nas folhas desta cultura.

Dentre os micronutrientes analisados, ocorreu diferença significativa apenas para o teor de cobre nas folhas das plantas de copo-de-leite com as doses de silício (figura 5). Verificouse que ocorreu redução no teor de cobre nas folhas até a dose $50,22 \mathrm{mg} \mathrm{dm}^{-3}$ de silício aplicada, aumentando posteriormente com a utilização de doses mais elevadas desse elemento.

A resposta da planta ao fornecimento de silício foi semelhante ao resultado obtido por POZZA (2004), que observou redução da eficiência de absorção de cobre nas 
mudas da variedade de café Icatu com as doses de silício até $0,48 \mathrm{~g} \mathrm{dm}^{-3}$ de silicato de cálcio, aumentando após esta concentração. Apesar de estatisticamente significativa, a variação do teor de cobre nas folhas das plantas de copo-deleite em função das doses de silício não foi importante do ponto de vista nutricional, não se observando sintomas de deficiência ou toxidez.

Não ocorreu diferença significativa entre os teores dos demais micronutrientes nas folhas de plantas de copo-de-leite em função dos tratamentos utilizados (tabela 7).

\subsection{Efeito das doses de silício na produção de inflorescências de copo-de-leite}

Verificou-se que o silício, nas concentrações utilizadas neste experimento, não influenciou, de forma significativa, a produção e a qualidade das inflorescências de copo-deleite. As plantas de copo-de-leite produziram, em média, durante o período experimental de 6 meses, 3 inflorescências, as quais apresentaram, em média, hastes com $25,19 \mathrm{~cm}$ de comprimento e $0,88 \mathrm{~cm}$ de diâmetro, espatas de $8,17 \mathrm{~cm}$ de largura e $8,27 \mathrm{~cm}$ de comprimento e $1,38 \mathrm{~g}$ de matéria seca (tabela 8).

Observou-se que as crescentes doses de silício utilizadas não influenciaram os teores de silício das inflorescências, os quais se apresentaram semelhantes à testemunha, cujo valor médio foi de 2,50 $\mathrm{g} \mathrm{kg}^{-1}$ (tabela 9). O silício é transportado pelo xilema e depositado na parede celular das células epidérmicas das folhas. Dependendo da forma em que é depositado, torna-se imóvel e não mais se redistribui na planta. Segundo KORNDÖRFER (2006), vários experimentos confirmam a baixa mobilidade do silício, pois, a partir de análises químicas em plantas cultivadas com fornecimento de silício, foi possível observar que estas apresentam maior concentração desse elemento nas folhas mais velhas. Como a redistribuição do silício nas plantas é bastante reduzida, possivelmente, não ocorreu translocação desse elemento para as inflorescências. Assim, pode-se inferir que os baixos teores de silício nas inflorescências de copo-de-leite, mesmo com o aumento do teor desse elemento nas folhas, foram decorrentes da sua baixa mobilidade nas plantas.

Para os teores de macronutrientes avaliados nas inflorescências de copo-de-leite, não se verificaram diferenças significativas entre os tratamentos (tabela 10), assim como para a concentração de micronutrientes (tabela 11).

Como observado em plantas de arroz cultivadas com aplicação de silício (SILVA e BOHNEN, 2001), a utilização de diferentes doses desse elemento para a cultura do copode-leite não proporcionou o efeito esperado e relatado em literatura. O silício não foi eficiente na produção e qualidade das inflorescências como descrito para outras culturas (BARBOSA FILHO et al., 2001; RODRIGUES, 2006). Segundo SILVA e BOHNEN (2001), tal comportamento poderia estar relacionado com as condições em que o experimento foi conduzido, ou seja, sem a ocorrência de algum estresse de ordem nutricional ou ambiental significativo, os quais ocorrem normalmente no campo. Além disso, a concentração de silício utilizada pode ter sido baixa para interferir no comportamento das plantas, sendo necessários novos estudos com doses mais elevadas e maior frequência de adubação.

\section{CONCLUSÕES}

A utilização de silicato de potássio aumenta o $\mathrm{pH}$ do substrato e a absorção de enxofre.

A adubação silicatada não influenciou o desenvolvimento e a produção de inflorescências de copo-de-leite.

\section{REFERÊNCIAS}

ALMEIDA, E. F. A., PAIVA, P. D. O. Floricultura 2: cultivo de copo-de-leite. Lavras: UFLA, 2004. 28p. Texto Acadêmico.

BARBOSA FILHO, M. P., SNYDER, G. H., FAGERIA, N. K., DATNOFF, L. E., SILVA, O. F. Silicato de cálcio como fonte de silício para o arroz sequeiro. Revista Brasileira de Ciência do Solo, Viçosa, v.25, n.2, p.325-330, 2001.

BRASIL. Ministério da Agricultura. Normais climatológicas: 1961-1990. Brasília: EMBRAPA/DNMET, 1992. 84 p.

FERREIRA, D. F. Análises estatísticas por meio do SISVAR para windows versão 4.0. In: REUNIÃO ANUAL DA REGIÃO BRASILEIRA DA SOCIEDADE INTERNACIONAL DE BIOMETRIA, 45, São Carlos, 2000. Anais... São Carlos, UFSCar, 2000. p.225-258.

FURLANI, A. M. C. Nutrição mineral. In: KERBAUY, G. B. Fisiologia vegetal. Rio de Janeiro: Guanabara Koogan, 2004. p.40-75.

FURTINI NETO, A. E., VALE, F. R., RESENDE, A. V., GUILHERME, L. R. G., GUEDES, G. A.de A. Fertilidade do solo. Lavras: UFLA/FAEPE, 2001. 252p.

GALLO, J. R., FURLANI, P. R. Determinação de silício em material vegetal pelo método colorimétrico do azul de molibdênio. Bragantia, Campinas, v.37, n.2, p.5-11, 1978.

KORNDÖRFER, G. H. Elementos benéficos. In: FERNANDES, M. S. Nutrição mineral de plantas. Viçosa: SBCS, 2006. p.355-374.

LANA, R. M. Q., KORNDÖRFER, G. H., ZANÃO JÚNIOR, L. A., SILVA, F.da, LANA, A. M. Q. Efeito do silicato de cálcio sobre a produtividade e acumulação de silício no tomateiro. Bioscience Journal, Uberlândia, v.19, n.2, p.1520, 2003.

MALAVOLTA, E., MURAOKA, T. Avaliação do estado nutricional e da fertilidade do solo: métodos de vegetação e diagnose por subtração em vasos. Piracicaba: CENA/USP, 1985. 7p. Mimeografado. 
MALAVOLTA, E., VITTI, G. C., OLIVEIRA, S. A. Avaliação do estado nutricional das plantas: princípios e aplicações. Piracicaba, 1997. 319p.

MALAVOLTA, E. Manual de nutrição mineral de plantas. São Paulo: Agronômica Ceres, 2006. 638p.

MAUAD, M., GRASSI FILHO, H., CRUSCIOL, C. A. C., CORREAA, J. C. Teores de silício no solo e na planta de arroz de terras altas com diferentes doses de adubação silicatada e nitrogenada. Revista Brasileira de Ciência do Solo, Viçosa, v.27, n.5, p.867-873, 2003.

MELLO, F. A. F., SOBRINHO, M. O. C. B., ARZOLLA, S., SILVEIRA, R. I., NETTO, A. C., KIEHL, J. C. Fertilidade do solo. Piracicaba: Nobel, 1983. 400p.

NOWAK, J., RUDNICKI, R. M. Postharvest handling and storage of cut flowers, florist greens and potted plants. Portland: Timber Press, 1990. 210p.

PEREIRA, H. S., VITTI, G. C., KORNDÖRFER, G. H. Comportamento de diferentes fontes de silício no solo e na cultura do tomateiro. Revista Brasileira de Ciência do Solo, Viçosa, v.27, n.1, p.101-108, 2003.

POZZA, A. A. A. Silício em mudas de cafeeiro: efeito na nutrição mineral e na suscetibilidade à cercosporiose em três variedades. Lavras: Universidade Federal de Lavras, 2004. 83p. Tese (Doutorado em Agronomia).

RODRIGUES, T. M. Produção de crisântemo cultivado em diferentes substratos fertirrigados com fósforo, potássio e silício. Lavras: Universidade Federal de Lavras, 2006. 84p.. Tese (Doutorado em Agronomia).

SALINGER, J. P. Producción comercial de flores. Zaragoza: Acribia, 1991. 371p.

SILVA, L. S., BOHNEN, H. Rendimento e acúmulo de nutrientes pelo arroz em solução nutritiva com e sem a adição de silício. Revista Brasileira de Ciência do Solo, Viçosa, v.25, n.3, p.771-777, 2001.

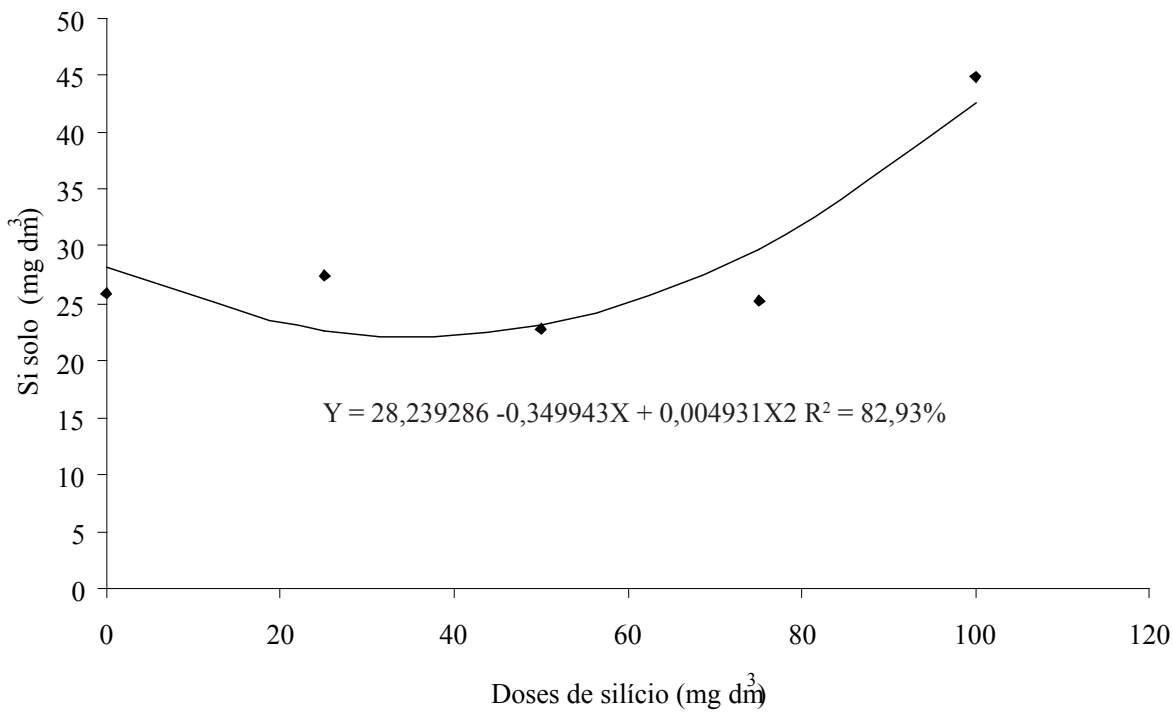

Figura 1. Alterações dos teores de silício $\left(\mathrm{mg} \mathrm{dm}^{-3}\right)$ no solo em função das diferentes doses silício aplicadas. Figure 1. Alterations on silicon content $\left(\mathrm{mg} \mathrm{dm}^{-3}\right)$ in soil according to different silicon levels applied. 


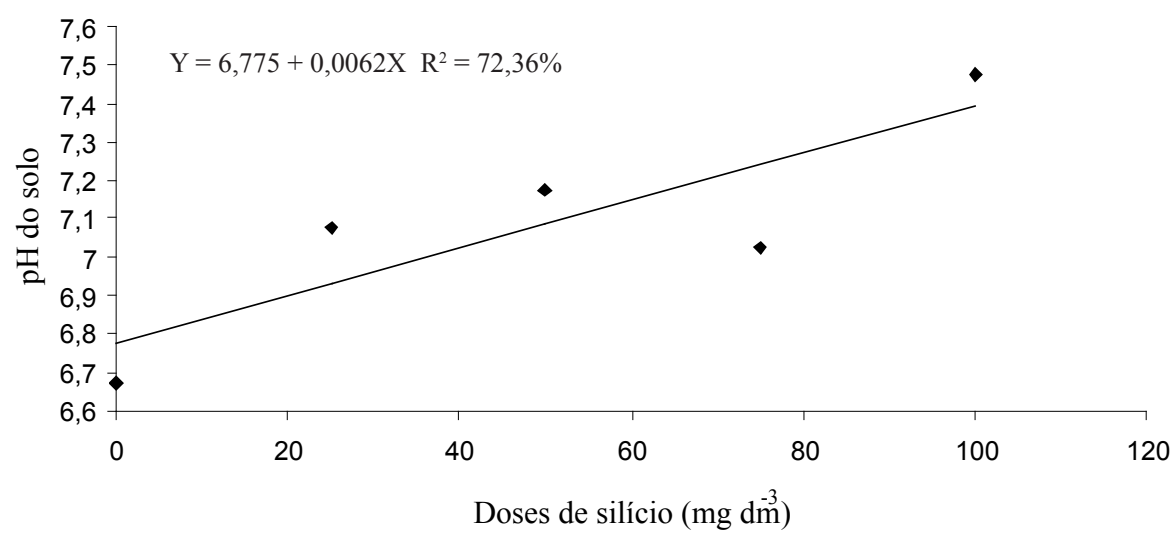

Figura 2. Alterações do $\mathrm{pH}$ do solo em função das diferentes doses de silício aplicadas.

Figure 2. Alterations on $\mathrm{pH}$ of the soil according to different silicon levels applied

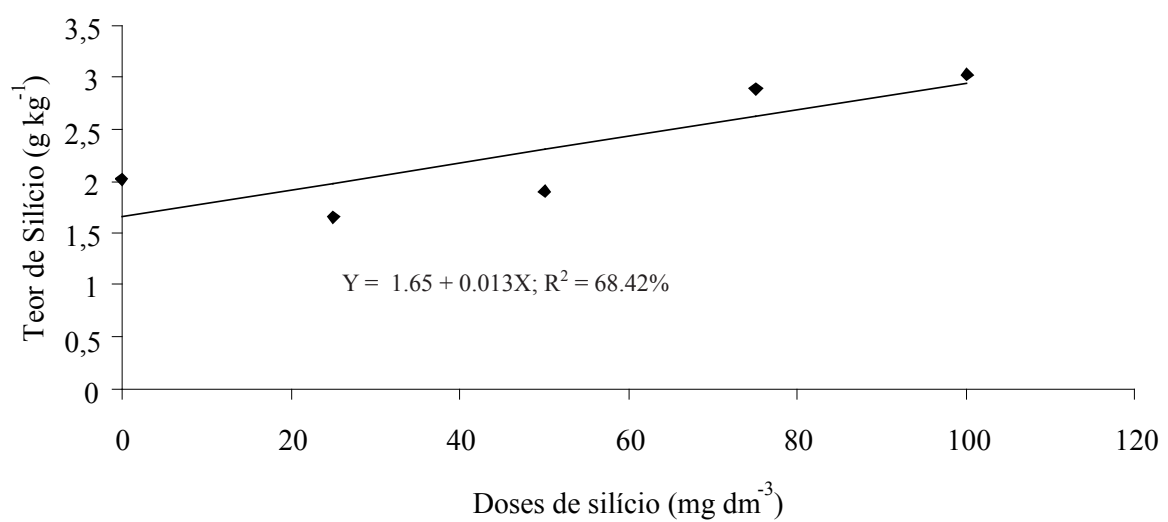

Figura 3. Teor de silício $\left(\mathrm{g} \mathrm{kg}^{-1}\right)$ nas folhas de copo-de-leite em função das diferentes doses de silício aplicadas.

Figure 3. Silicon content $\left(\mathrm{g} \mathrm{kg}^{-1}\right)$ in calla lily leaves according to different silicon levels applied.

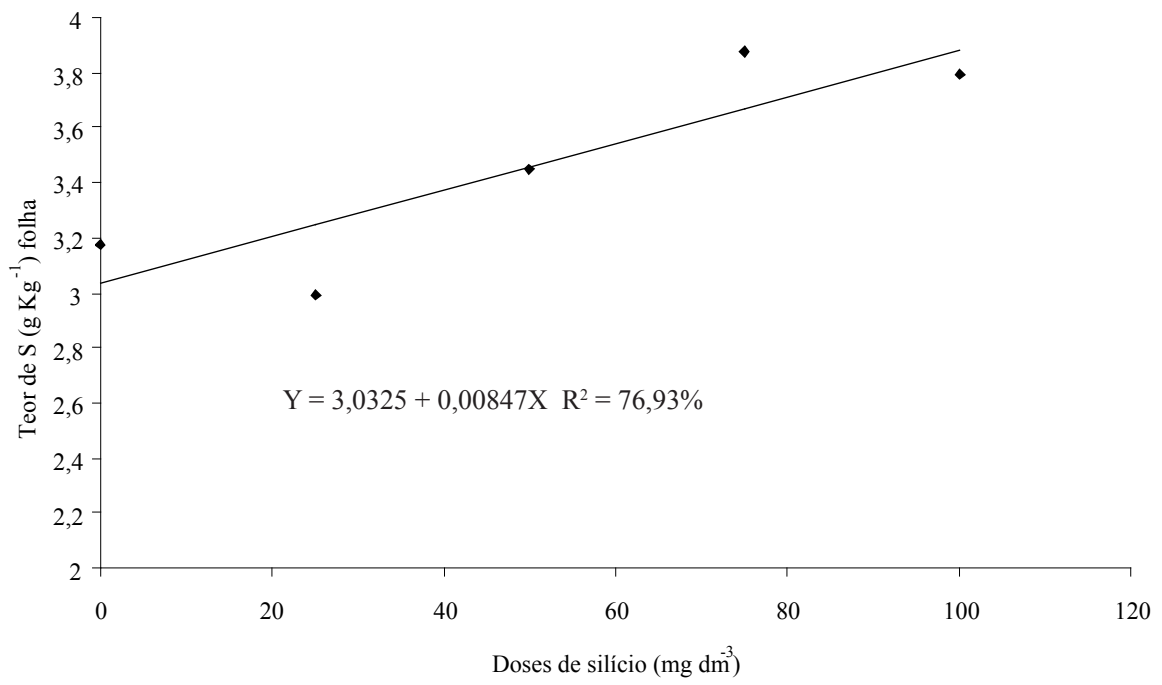

Figura 4. Teor de enxofre $\left(\mathrm{g} \mathrm{kg}^{-1}\right)$ nas folhas de copo-de-leite em função das diferentes doses de silício aplicadas. Figure 4. Sulfur content $\left(\mathrm{g} \mathrm{kg}^{-1}\right)$ in calla lily leaves according to different silicon levels applied. 


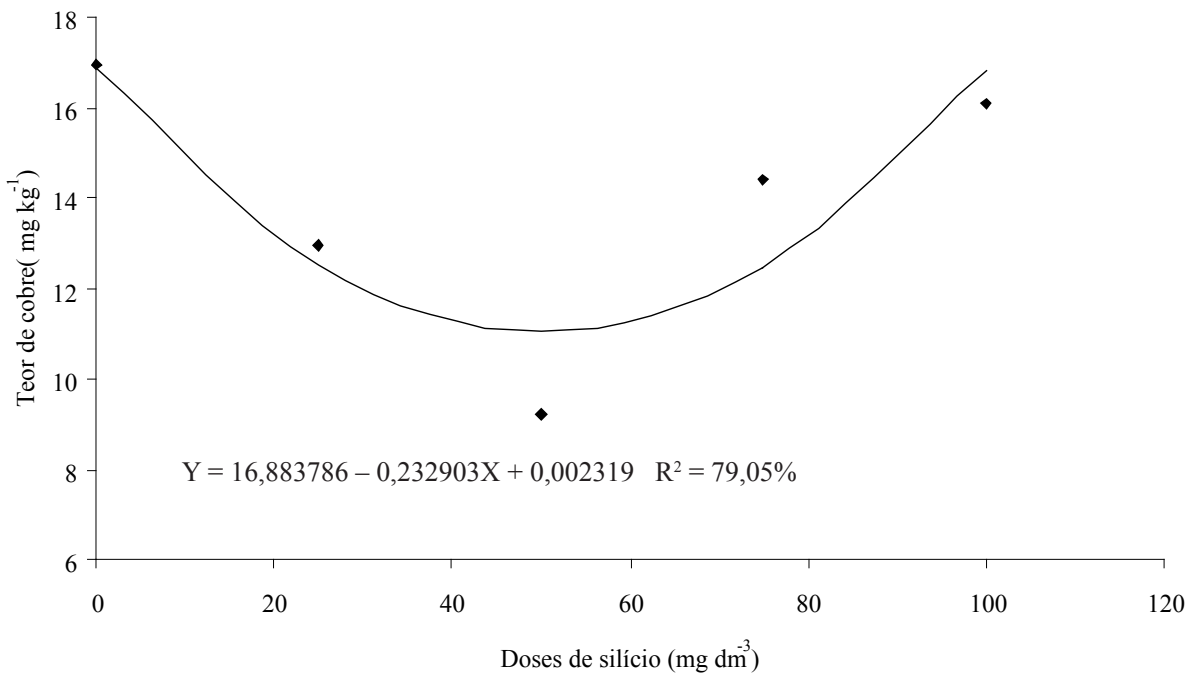

Figura 5. Teor de cobre $\left(\mathrm{mg} \mathrm{kg}^{-1}\right)$ nas folhas de copo-de-leite em função das diferentes doses de silício aplicadas.

Figure 5. Copper content $\left(\mathrm{mg} \mathrm{kg}^{-1}\right)$ in calla lily leaves according to different silicon levels applied.

Tabela 1. Características do substrato utilizado para cultivo de plantas de copo-de-leite antes da aplicação dos tratamentos. UFLA, Lavras, MG, 2007.

Table 1. Characteristics of the substrate utilized to calla lily plants cultivation before treatments application. UFLA, Lavras, MG, 2007.

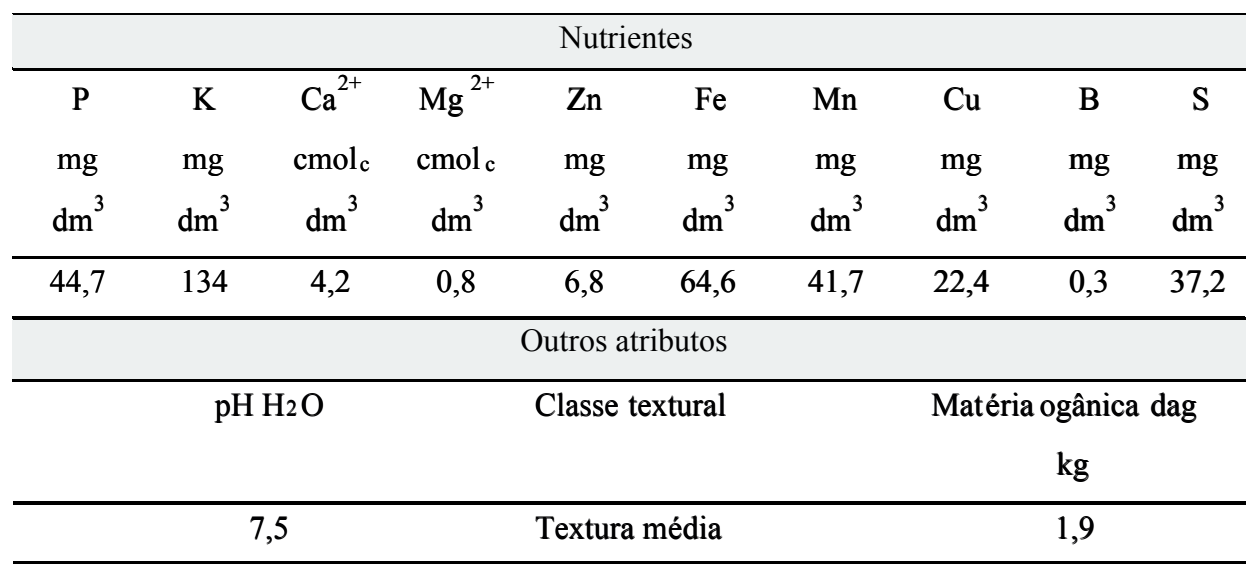


Tabela 2. Teores médios de macronutrientes no solo em função das diferentes doses de silício aplicadas. UFLA, Lavras, MG, 2007.

Table 2. Average contents of macronutrients in soil according to different silicon levels applied. UFLA, Lavras, MG, 2007.

\begin{tabular}{cccccc}
\hline $\begin{array}{c}\text { Doses de Si } \\
\left(\mathrm{mg} \mathrm{dm}^{-3}\right)\end{array}$ & $\begin{array}{c}\mathrm{P} \\
\left(\mathrm{mg} \mathrm{dm}^{-3}\right)\end{array}$ & $\begin{array}{c}\mathrm{K} \\
\left(\mathrm{mg} \mathrm{dm}^{-3}\right)\end{array}$ & $\begin{array}{c}\mathrm{Ca} \\
\left(\mathrm{cmolc} \mathrm{dm}^{-3}\right)\end{array}$ & $\begin{array}{c}\mathrm{Mg} \\
\left(\mathrm{cmolc} \mathrm{dm}^{-3}\right)\end{array}$ & $\begin{array}{c}\mathrm{S} \\
\left(\mathrm{mg} \mathrm{dm}^{-3}\right)\end{array}$ \\
\hline 0 & $122,15 \mathrm{a}$ & $140,25 \mathrm{a}$ & $10,13 \mathrm{a}$ & $0,95 \mathrm{a}$ & $122,63 \mathrm{a}$ \\
25 & $145,53 \mathrm{a}$ & $177,75 \mathrm{a}$ & $9,75 \mathrm{a}$ & $0,88 \mathrm{a}$ & $108,05 \mathrm{a}$ \\
50 & $139,83 \mathrm{a}$ & $135,75 \mathrm{a}$ & $9,88 \mathrm{a}$ & $0,85 \mathrm{a}$ & $110,18 \mathrm{a}$ \\
75 & $128,20 \mathrm{a}$ & $146,50 \mathrm{a}$ & $10,25 \mathrm{a}$ & $0,93 \mathrm{a}$ & $108,43 \mathrm{a}$ \\
100 & $112,65 \mathrm{a}$ & $109,00 \mathrm{a}$ & $9,38 \mathrm{a}$ & $0,78 \mathrm{a}$ & $110,18 \mathrm{a}$ \\
Média & 129,67 & 141,85 & 9,88 & 0,88 & 111,89 \\
\hline
\end{tabular}

Tabela 3. Teores médios de micronutrientes no solo em função das diferentes doses de silício aplicadas. UFLA, Lavras, MG, 2007.

Table 3. Average contents of micronutrients in soil according to different silicon levels applied. UFLA, Lavras, MG, 2007.

\begin{tabular}{cccccc}
\hline Doses de Si mg dm $^{-3}$ & $\begin{array}{c}\mathrm{B} \\
\mathrm{mg} \mathrm{dm}^{-3}\end{array}$ & $\begin{array}{c}\mathrm{Fe} \\
\mathrm{mg} \mathrm{dm}^{-3}\end{array}$ & $\begin{array}{c}\mathrm{Mn} \\
\mathrm{mg} \mathrm{dm}^{-3}\end{array}$ & $\begin{array}{c}\mathrm{Zn} \\
\mathrm{mg} \mathrm{dm}^{-3}\end{array}$ & $\begin{array}{c}\mathrm{Cu} \\
\mathrm{mg} \mathrm{dm}^{-3}\end{array}$ \\
\hline 0 & $0,35 \mathrm{a}$ & $70,50 \mathrm{a}$ & $59,10 \mathrm{a}$ & $12,43 \mathrm{a}$ & $5,85 \mathrm{a}$ \\
25 & $0,41 \mathrm{a}$ & $75,33 \mathrm{a}$ & $62,10 \mathrm{a}$ & $15,68 \mathrm{a}$ & $7,48 \mathrm{a}$ \\
50 & $0,30 \mathrm{a}$ & $72,70 \mathrm{a}$ & $61,60 \mathrm{a}$ & $15,15 \mathrm{a}$ & $7,60 \mathrm{a}$ \\
75 & $0,36 \mathrm{a}$ & $69,38 \mathrm{a}$ & $63,73 \mathrm{a}$ & $14,25 \mathrm{a}$ & $5,83 \mathrm{a}$ \\
100 & $0,30 \mathrm{a}$ & $74,15 \mathrm{a}$ & $57,38 \mathrm{a}$ & $12,43 \mathrm{a}$ & $5,88 \mathrm{a}$ \\
Média & 0,34 & 72,41 & 60,78 & 13,99 & 6,53 \\
\hline
\end{tabular}

Tabela 4. Médias das características agronômicas de desenvolvimento das plantas de copo-de-leite cultivadas em diferentes doses de silício. UFLA, Lavras, MG, 2007.

Table 4. Mean values of agronomic development characteristics of calla lily plants cultivated in different silicon levels. UFLA, Lavras, MG, 2007.

\begin{tabular}{ccccccc}
\hline $\begin{array}{c}\text { Doses Si } \\
\left(\mathrm{mg} \mathrm{dm}^{3}\right)\end{array}$ & $\mathrm{N}^{\mathrm{o}}$ folhas & Altura $(\mathrm{cm})$ & $\begin{array}{c}\text { Comprimento } \\
\text { Folha }(\mathrm{cm})\end{array}$ & $\begin{array}{c}\text { Largura } \\
\text { folha }(\mathrm{cm})\end{array}$ & $\begin{array}{c}\mathrm{N}^{\mathrm{o}} \\
\text { brotos }\end{array}$ & $\begin{array}{c}\mathrm{N}^{\mathrm{o}} \text { folhas por } \\
\text { brotos }\end{array}$ \\
\hline 0 & $5,08 \mathrm{a}$ & $18,70 \mathrm{a}$ & $17,30 \mathrm{a}$ & $11,94 \mathrm{a}$ & $5,42 \mathrm{a}$ & $19,67 \mathrm{a}$ \\
25 & $5,67 \mathrm{a}$ & $18,43 \mathrm{a}$ & $16,56 \mathrm{a}$ & $11,08 \mathrm{a}$ & $5,50 \mathrm{a}$ & $19,50 \mathrm{a}$ \\
50 & $5,75 \mathrm{a}$ & $18,93 \mathrm{a}$ & $16,42 \mathrm{a}$ & $11,92 \mathrm{a}$ & $4,75 \mathrm{a}$ & $15,96 \mathrm{a}$ \\
75 & $5,42 \mathrm{a}$ & $18,90 \mathrm{a}$ & $16,58 \mathrm{a}$ & $11,93 \mathrm{a}$ & $6,17 \mathrm{a}$ & $17,83 \mathrm{a}$ \\
100 & $5,42 \mathrm{a}$ & $17,88 \mathrm{a}$ & $16,21 \mathrm{a}$ & $11,87 \mathrm{a}$ & $5,58 \mathrm{a}$ & $16,92 \mathrm{a}$ \\
Média & 5,47 & 18,57 & 16,61 & 11,75 & 5,48 & 17,98 \\
\hline
\end{tabular}


Tabela 5. Massa de matéria seca (MS) das folhas, rizomas e raízes de plantas de copo-de-leite cultivadas em diferentes doses de silício. UFLA, Lavras, MG, 2007.

Table 5. Dry matter (DM) of leaves, rhizomes and roots of calla lily plants cultivated in different silicon levels. UFLA, Lavras, MG, 2007.

\begin{tabular}{cccc}
\hline Doses Si $\left(\mathrm{mg} \mathrm{dm}^{3}\right)$ & MS da folha $(\mathrm{g})$ & MS do rizoma $(\mathrm{g})$ & MS da raiz $(\mathrm{g})$ \\
\hline 0 & $8,72 \mathrm{a}$ & $15,17 \mathrm{a}$ & $4,48 \mathrm{a}$ \\
25 & $8,90 \mathrm{a}$ & $14,86 \mathrm{a}$ & $4,78 \mathrm{a}$ \\
50 & $8,36 \mathrm{a}$ & $13,28 \mathrm{a}$ & $5,20 \mathrm{a}$ \\
75 & $8,30 \mathrm{a}$ & $13,95 \mathrm{a}$ & $4,76 \mathrm{a}$ \\
100 & $7,07 \mathrm{a}$ & $15,26 \mathrm{a}$ & $4,42 \mathrm{a}$ \\
\hline Média & 8,27 & 14,50 & 4,73 \\
\hline
\end{tabular}

Tabela 6. Teores médios de macronutrientes nas folhas de plantas de copo-de-leite em função de diferentes doses de silício aplicadas. UFLA, Lavras, MG, 2007.

Table 6. Average contents of macronutrients in leaves of calla lily plants according to different silicon levels applied. UFLA, Lavras, MG, 2007.

\begin{tabular}{cccccc}
\hline $\begin{array}{c}\text { Doses de Si } \\
\mathrm{mg} \mathrm{dm}^{-3}\end{array}$ & $\begin{array}{c}\mathrm{N} \\
\mathrm{g} \mathrm{kg}^{-1}\end{array}$ & $\begin{array}{c}\mathrm{P} \\
\mathrm{g} \mathrm{kg}^{-1}\end{array}$ & $\begin{array}{c}\mathrm{K} \\
\mathrm{g} \mathrm{kg}^{-1}\end{array}$ & $\begin{array}{c}\mathrm{Ca} \\
\mathrm{g} \mathrm{kg}^{-1}\end{array}$ & $\begin{array}{c}\mathrm{Mg} \\
\mathrm{g} \mathrm{kg}^{-1}\end{array}$ \\
\hline 0 & $36,32 \mathrm{a}$ & $3,46 \mathrm{a}$ & $24,75 \mathrm{a}$ & $12,66 \mathrm{a}$ & $1,68 \mathrm{a}$ \\
25 & $38,85 \mathrm{a}$ & $3,54 \mathrm{a}$ & $25,50 \mathrm{a}$ & $13,43 \mathrm{a}$ & $1,69 \mathrm{a}$ \\
50 & $38,36 \mathrm{a}$ & $3,64 \mathrm{a}$ & $24,90 \mathrm{a}$ & $13,83 \mathrm{a}$ & $1,66 \mathrm{a}$ \\
75 & $38,37 \mathrm{a}$ & $3,49 \mathrm{a}$ & $24,30 \mathrm{a}$ & $15,10 \mathrm{a}$ & $1,72 \mathrm{a}$ \\
100 & $40,87 \mathrm{a}$ & $3,86 \mathrm{a}$ & $27,40 \mathrm{a}$ & $13,10 \mathrm{a}$ & $1,62 \mathrm{a}$ \\
Média & 38,55 & 3,60 & 25,37 & 13,62 & 1,67 \\
\hline
\end{tabular}

Tabela 7. Teores médios de micronutrientes nas folhas de plantas de copo-de-leite em função de diferentes doses de silício aplicadas. UFLA, Lavras, MG, 2007.

Table 7. Average contents of micronutrients in leaves of calla lily plants according to different silicon levels applied. UFLA, Lavras, MG, 2007.

\begin{tabular}{ccccc}
\hline $\begin{array}{c}\text { Doses de Si } \\
\mathrm{mg} \mathrm{dm}^{-3}\end{array}$ & $\begin{array}{c}\mathrm{B} \\
\mathrm{mg} \mathrm{kg}^{-1}\end{array}$ & $\begin{array}{c}\mathrm{Fe} \\
\mathrm{mg} \mathrm{kg}^{-1}\end{array}$ & $\begin{array}{c}\mathrm{Mn} \\
\mathrm{mg} \mathrm{kg}^{-1}\end{array}$ & $\begin{array}{c}\mathrm{Zn} \\
\mathrm{mg} \mathrm{kg}^{-1}\end{array}$ \\
\hline 0 & $41,87 \mathrm{a}$ & $161,55 \mathrm{a}$ & $36,92 \mathrm{a}$ & $70,34 \mathrm{a}$ \\
25 & $42,52 \mathrm{a}$ & $161,55 \mathrm{a}$ & $32,60 \mathrm{a}$ & $73,10 \mathrm{a}$ \\
50 & $43,64 \mathrm{a}$ & $179,94 \mathrm{a}$ & $40,33 \mathrm{a}$ & $65,72 \mathrm{a}$ \\
75 & $41,68 \mathrm{a}$ & $173,34 \mathrm{a}$ & $37,07 \mathrm{a}$ & $72,61 \mathrm{a}$ \\
100 & $44,23 \mathrm{a}$ & $198,69 \mathrm{a}$ & $32,31 \mathrm{a}$ & $71,67 \mathrm{a}$ \\
Média & 42,79 & 175,01 & 35,85 & 70,69 \\
\hline
\end{tabular}


Tabela 8. Número de inflorescências produzidas (NI), comprimento da haste (CH), diâmetro da haste (DH), largura da espata (LE), comprimento da espata (CE) e massa de matéria seca das inflorescências de copo-de-leite (MSI) em diferentes doses de silício aplicadas. UFLA, Lavras, MG, 2007.

Table 8. Number of inflorescences produced (NI), stem length (SL), stem diameter (SD), spathe width (SW), spathe length (SPL) and dry matter of calla lily inflorescences (DMI) in different silicon levels applied. UFLA, Lavras, MG, 2007.

\begin{tabular}{ccccccc}
\hline Doses Si mg dm & NI & CH $(\mathrm{cm})$ & DH $(\mathrm{cm})$ & LE $(\mathrm{cm})$ & CE $(\mathrm{cm})$ & MSI $(\mathrm{g})$ \\
\hline 0 & $2,50 \mathrm{a}$ & $23,42 \mathrm{a}$ & $0,83 \mathrm{a}$ & $8,06 \mathrm{a}$ & $8,27 \mathrm{a}$ & $1,27 \mathrm{a}$ \\
25 & $3,09 \mathrm{a}$ & $24,19 \mathrm{a}$ & $0,82 \mathrm{a}$ & $7,93 \mathrm{a}$ & $7,88 \mathrm{a}$ & $1,34 \mathrm{a}$ \\
50 & $3,08 \mathrm{a}$ & $24,36 \mathrm{a}$ & $0,83 \mathrm{a}$ & $8,14 \mathrm{a}$ & $7,93 \mathrm{a}$ & $1,37 \mathrm{a}$ \\
75 & $2,56 \mathrm{a}$ & $23,67 \mathrm{a}$ & $0,88 \mathrm{a}$ & $8,52 \mathrm{a}$ & $8,75 \mathrm{a}$ & $1,47 \mathrm{a}$ \\
100 & $2,67 \mathrm{a}$ & $25,33 \mathrm{a}$ & $0,86 \mathrm{a}$ & $8,22 \mathrm{a}$ & $8,51 \mathrm{a}$ & $1,43 \mathrm{a}$ \\
Média & 2,78 & 24,19 & 0,84 & 8,17 & 8,27 & 1,38 \\
\hline
\end{tabular}

Tabela 9. Teores médios de silício nas inflorescências de copo-de-leite em função de diferentes doses de silício aplicadas. UFLA, Lavras, MG, 2007.

Table 9. Average contents of silicon in calla lily inflorescences according to different silicon levels applied. UFLA, Lavras, MG, 2007.

\begin{tabular}{cc}
\hline Doses Si mg dm $^{3}$ & ${\text { Si inflorescência } \mathrm{g} \mathrm{kg}^{-1}}^{-1}$ \\
\hline 0 & $2,53 \mathrm{a}$ \\
50 & $2,90 \mathrm{a}$ \\
75 & $2,40 \mathrm{a}$ \\
100 & $2,40 \mathrm{a}$ \\
Média & $2,28 \mathrm{a}$ \\
\hline
\end{tabular}

Tabela 10. Teores médios de macronutrientes nas inflorescências de copo-de-leite em função de diferentes doses de silício aplicadas. UFLA, Lavras, MG, 2007.

Table 10. Average contents of macronutrients in calla lily inflorescences according to different silicon levels applied. UFLA, Lavras, MG, 2007.

\begin{tabular}{|c|c|c|c|c|c|c|}
\hline Doses $\mathrm{Si}\left(\mathrm{mg} \mathrm{dm}^{-3}\right)$ & $\begin{array}{c}\mathrm{N} \\
\left(\mathrm{g} \mathrm{kg}^{-1}\right)\end{array}$ & $\begin{array}{c}\mathrm{P} \\
\left(\mathrm{g} \mathrm{kg}^{-1}\right)\end{array}$ & $\frac{\mathrm{K}}{\left(\mathrm{g} \mathrm{kg}^{-1}\right)}$ & $\begin{array}{c}\mathrm{Ca} \\
\left(\mathrm{g} \mathrm{kg}^{-1}\right)\end{array}$ & $\begin{array}{c}\mathrm{Mg} \\
\left(\mathrm{g} \mathrm{kg}^{-1}\right)\end{array}$ & $\frac{\mathrm{S}}{\left(\mathrm{g} \mathrm{kg}^{-1}\right)}$ \\
\hline 0 & $37,34 \mathrm{a}$ & $4,42 \mathrm{a}$ & $28,20 \mathrm{a}$ & $9,85 \mathrm{a}$ & $1,69 \mathrm{a}$ & $3,05 \mathrm{a}$ \\
\hline 25 & $36,80 \mathrm{a}$ & $4,68 \mathrm{a}$ & $26,40 \mathrm{a}$ & $9,95 \mathrm{a}$ & $1,64 \mathrm{a}$ & $2,83 \mathrm{a}$ \\
\hline 50 & $38,62 \mathrm{a}$ & $4.84 \mathrm{a}$ & $27,15 \mathrm{a}$ & $9,83 \mathrm{a}$ & $1,64 \mathrm{a}$ & $2,77 \mathrm{a}$ \\
\hline 75 & $38,72 \mathrm{a}$ & $4,81 \mathrm{a}$ & $27,45 \mathrm{a}$ & $9,97 \mathrm{a}$ & $1,72 \mathrm{a}$ & $2,89 \mathrm{a}$ \\
\hline 100 & $37,88 \mathrm{a}$ & $4,51 \mathrm{a}$ & $27,00 \mathrm{a}$ & $10,29 \mathrm{a}$ & $1,73 \mathrm{a}$ & $2,78 \mathrm{a}$ \\
\hline Média & 37,87 & 4,65 & 27,24 & 9,99 & 1,68 & 2,86 \\
\hline
\end{tabular}


Tabela 11. Teores médios de micronutrientes nas inflorescências de copo-de-leite em função de diferentes doses de silício aplicadas. UFLA, Lavras, MG, 2007.

Table 11. Average contents of micronutrients in calla lily inflorescences according to different silicon levels applied. UFLA, Lavras, MG, 2007.

\begin{tabular}{ccccc}
\hline $\begin{array}{c}\text { Doses Si mg } \\
\mathrm{dm}^{-3}\end{array}$ & $\begin{array}{c}\mathrm{B} \\
\mathrm{mg} \mathrm{kg}^{-1}\end{array}$ & $\begin{array}{c}\mathrm{Fe} \\
\mathrm{mg} \mathrm{kg}^{-1}\end{array}$ & $\begin{array}{c}\mathrm{Mn} \\
\mathrm{mg} \mathrm{kg}^{-1}\end{array}$ & $\begin{array}{c}\mathrm{Zn} \\
\mathrm{mg} \mathrm{kg}^{-1}\end{array}$ \\
\hline 0 & $57,35 \mathrm{a}$ & $89,30 \mathrm{a}$ & $35,72 \mathrm{a}$ & $91,97 \mathrm{a}$ \\
25 & $51,90 \mathrm{a}$ & $92,04 \mathrm{a}$ & $35,86 \mathrm{a}$ & $94,56 \mathrm{a}$ \\
50 & $53,52 \mathrm{a}$ & $64,11 \mathrm{a}$ & $30,74 \mathrm{a}$ & $85,36 \mathrm{a}$ \\
75 & $49,40 \mathrm{a}$ & $84,17 \mathrm{a}$ & $35,93 \mathrm{a}$ & $87,72 \mathrm{a}$ \\
100 & $57,63 \mathrm{a}$ & $86,01 \mathrm{a}$ & $38,76 \mathrm{a}$ & $83,91 \mathrm{a}$ \\
Média & 53,96 & 83,13 & 35,40 & 88,70 \\
\hline
\end{tabular}

